\title{
CALIBRATION OF ELECTROSTATIC ANTENNAS USING BROADCAST SIGNAL
}

\author{
M.Ishii, T.Kawamura, J.Hojyo, \\ Institute of Industrial Science, Univ, of Tokyo, Tokyo 106 \\ and T. Iwaizumi \\ Tohoku Electric Power Co., Sendai 980
}

\begin{abstract}
A simple and practical method in the calibration of electrostatic antennas has been developed. This is achieved by measuring VLF or LF broadcast signal strength induced on the antennas. The principle and details of this method are stated, and the results of the application to the calibration of lightning flash counters and a field mill are given, which proved the practicability and effectiveness of this method.
\end{abstract}

\section{Introduction}

Electrostatic antennas and similar equipment based on the same principle are commonly used to observe electric field in the low frequency range, including DC. And in most cases, accurate calibration of the antenna is essential. In the course of the development of compact lightning flash counters which have the same property as CIGRE $500 \mathrm{~Hz}$ counter, a simple method of calibration of an electrostatic antenna using LF or VLF broadcast signals was realized. This is more practical than the method proposed by Clayton et al. (1973) in calibrating the electrostatic antenna for the measurement of ELF signal. An extensive application of this method to a field mill is also tried. In this report, the proposed method and the results obtained by its application are presented together with some discussion.

\section{Principle of the calibration using broadcast signals}

The equivalent circuit of an electrostatic antenna connected to a measuring apparatus is shown in Fig. 1 together with the notes regarding the parameters. For the calibration of an electrostatic antenna, the evaluation of its effective height $h$ and antenna capacitance $\mathrm{Ca}$ is essential. The estimation of $h$ of antenna with complicated shape or in the vicinity of obstacles, is difficult by analytical method, but is possible by the measurement of the output voltage $\mathrm{V}$ under $\mathrm{AC}$ electric field of constant frequency and known intensity, when the values of $\mathrm{Ca}, \mathrm{C}$ and $\mathrm{R}$ are known. These circuit parameters can easily be mesdured by a bridge circuit. For the convenience of above measurement, it will be desirable if a broadcast radio signal can be used as the source of the electric field.

The induced voltage on an electrostatic antenna is dominated by the electric field. Considering the operation of an antenna against an electromagnetic wave, it acts as an electrostatic antenna provided that the electric field around it originating from the electromagnetic wave shows the same pattern as the one of the electrostatic field. This condition is met by electromagnetic waves of very low frequency, whose wave lengths are much larger than the dimensions of the antennas or shielding objects such as buildings or trees. This is justified as the pattern of scattered field induced by an electromagnetic wave of very low frequency, not far from the ground, is hardly distinguishable from that of electrostatic field. 


\section{ISHII ET AL.}

The highest frequency applicable to this calibration method is also limited by the relaxation time of induced charge on the ground and surrounding obstacles. The relaxation time of the ground is less than $5 \mu \mathrm{s}$ even in the adverse condition, and the one for the concrete is still less. So that broadcast signals lower? than $100 \mathrm{kHz}$ is used for our purpose. The evaluation of the unfavorable effect due to nearby ferromagnetic material is also made from the viewpoint of the skin depth. It increases as the frequency becomes lower, and for the iron, it is a few $\mathrm{mm}$ even at the frequency of 10 $\mathrm{Hz}$, which means that the unfavorable effect of the iron structure nearby is negligiblly small. From these, it is concluded in almost cases, broadcast signals lower than $100 \mathrm{kHz}$ can be used in the calibration of electrostatic antenna designed to measure the signal from DC to LF.

The use of broadcast signal of low frequency is also convenient because of its longer propagation distance and relatively stable signal intensity at receiving sites, which enables the improvement of the accuracy in the measurement by averaging the signal in a certain period. But the variation of the signal intensity (Echizenya et al. 1974) sometimes exceeds several dB within 10 minutes in the propagation distance of a few hundreds of kilometers. So that, simultaneous measurement between the standard antenna and the antenna in concern using 2 sets of receivers is preferred to obtain reliable result.

3. Application to the calibration of lightning flash counters

The shape of antennas is one of the important factors (Ishii et al. 1979) in designing lightning flash counters, from the viewpoint of eliminating anomalous counts ( Ishii et al. 1978). Shown in Fig. 2 are the side views of counters designed to eliminate anomalous counts, and the ratios of induced voltages on the antennas were measured using broadcast signals. The main antenna of the counter in Fig. 2(a) is calibrated beforehand and can be used as a standard. The results in Table 1 shows good agreement among the ratios obtained by different procedures. Based on the result of Table 1 , the sensitivity of the ring antenna type counter shown in Fig. 2(b) was adjusted. The result of the observation of lightning flashes by the vertical antenna type and ring antenna type counter is presented in Table 2, which shows good agreement. From this, it was made clear that the calibration of antennas of any shape can be practically achieved using broadcast signal.

Another subject is the sensitivity adjustment of counters sited in the vicinity of shielding objects. If the geometry of an installation site is simple, the shielding effect of obstacles to the antenna is quantitatively known by 3-dimentional field analysis. For the same purpose, experimental study using small scale model was performed (Prentice et al. 1975). But the proposed method utilizing broadcast signal is more practical both in accuracy and simplicity of the procedure. Thus, simultaneous measurement of induced voltages on the antennas was carried out at different installation sites shown in Fig. 3. The result corresponding to the two broadcast signals is presented in Table 3, which shows that the ratio of the induced voltages on the two antennas is independent of frequency. This means that these antennas operate as electrostatic antennas at these frequencies or below. Table 2 shows the number of registration of two counters located at different sites, whose sensitivities have been adjusted according to the result shown in Table 3. The discrepancy of these values is shown to be negligibly small, which proves that this method for sensitivity adjustment is very reliavle and satisfactory. 
M. ISHII ET AL.

Table 1. Ratios of induced voltages on antennas shown in Fig. 2

\begin{tabular}{|c|c|c|c|}
\hline & main antenna & sub antenna & ring antenna \\
\hline A & 1.0 & 0.34 & 0.35 \\
\hline B & 1.0 & 0.32 & - \\
\hline C & 1.0 & 0.36 & - \\
\hline D & 1.0 & 0.33 & - \\
\hline
\end{tabular}

A: obtained by the measurement of $40 \mathrm{kHz}$ broadcast signal

$\begin{array}{llll}\text { B: } & " & 13.6 & \\ \text { C: } & \text { " } & \text { the computation } & \end{array}$

Table 2. Registrations of lightning flash counters(Aug. 1979, at Tokyo)

\begin{tabular}{|c|r|r|c|}
\hline date & A & B & C \\
\hline 2 & 15 & 12 & $=$ \\
\hline 3 & 9 & 8 & $=$ \\
\hline 4 & 5 & 5 & - \\
\hline 6 & 36 & 37 & - \\
\hline 8 & 12 & 8 & $=$ \\
\hline 11 & 1558 & 1548 & - \\
\hline 12 & 94 & 96 & - \\
\hline 18 & 122 & 108 & - \\
\hline 19 & 36 & 26 & 28 \\
\hline 20 & 55 & 48 & 49 \\
\hline 21 & 59 & 46 & 47 \\
\hline 22 & 115 & 98 & 99 \\
\hline 23 & 10 & 11 & 10 \\
\hline 24 & 255 & 248 & 239 \\
\hline 29 & 10 & 9 & 11 \\
\hline tota1 & 2391 & 2302 & 483 \\
\hline ratio & 1.04 & 1.0 & 1.0 \\
\hline
\end{tabular}

$A_{-}$: Vertical antenna type counter on the building

B : Vertical antenna type counter on the ground

C : Ring antenna type counter on the building

Table 3. Induced voltage on the vertical antennas by the broadcast signal

\begin{tabular}{|c|c|c|c|c|c|c|}
\hline & \multicolumn{4}{|c|}{$40 \mathrm{KIz}$} & \multicolumn{2}{c|}{$13.6 \mathrm{KHI}$} \\
\cline { 2 - 7 } & $\begin{array}{c}\text { induced vol tage } \\
(\mathrm{mV} p-\mathrm{p})\end{array}$ & ratio & $\begin{array}{c}\text { induced voltage } \\
(\mathrm{mV} \mathrm{p}-\mathrm{p})\end{array}$ & ratio & $\begin{array}{c}\text { induced vol tage } \\
(\mathrm{mV} \mathrm{p}-\mathrm{p})\end{array}$ & ratio \\
\hline $\begin{array}{c}\text { counter } \\
\text { on the roof }\end{array}$ & 24.3 & 1.42 & 23.8 & 1.42 & 18.7 & 1.42 \\
\hline $\begin{array}{c}\text { counter } \\
\text { on the ground }\end{array}$ & - & - & 12.5 & 0.74 & - & - \\
\hline $\begin{array}{c}\text { counter without } \\
\text { adjacent objects }\end{array}$ & 17.1 & 1.0 & - & - & 13.2 & 1.0 \\
\hline
\end{tabular}

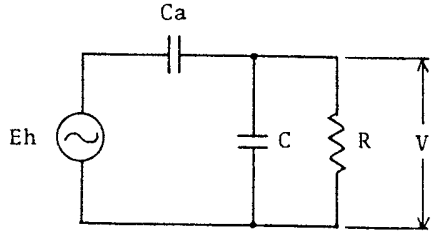

E : electric field intensity

$h$ : effective height of antenna

$\mathrm{V}$ : output voltage of antenna

$\mathrm{Ca}$ : antenna capacitance

$C, R$ : capacitance and resistance of input circuit of apparatus

Fig. 1. Equivalent circuit of an antenna connected to a measuring apparatus

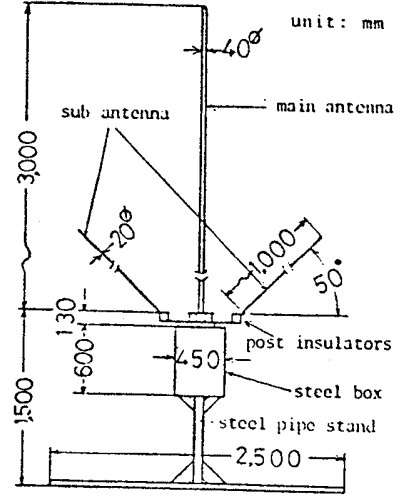

(a) Improved vertical antenna type counter

Fig. 2. Side views of lightning flash counters

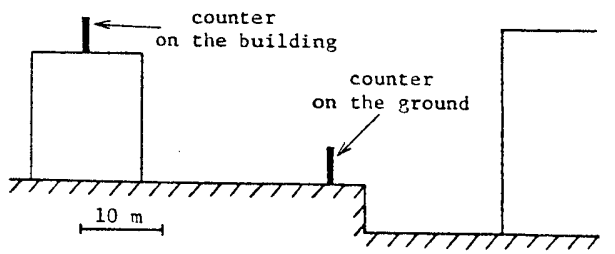

Fig. 3. Site installation corresponds to Table 3 


\section{ISHII ET AL.}

4. Application to the calibration of a feild mill

The operation of a field mill is based on the same principle as the electrostatic antenna. The slight difference is periodical shielding of an antenna (signal electrode of the field mill), whih enables the measurement of DC electeic field. The calibration of the field mill is usually carried out through the comparison of the records of natural electrostatic field with a horizontal antenna installed nearby. The fluctuation of field intensity in time and space, which originates from the locally drifting space charge, is one of the problem in this calibration.

The method using a broadcast signal is also considered to be capable of applicating to the calibration of a field mill. It is convenient that the effect of drifting space charge is neglected in this measurement since the broadcast signal is used as a source of the electric field. But the induced broadcast signal on the field mill is estimated to be extremely small due to the significantly reduced effective height. To confirm the feasibility of the calibration by the proposed method, the measurement of the induced voltage was carried out at a field mill of inverted type. The obtained signal to noise ratio was about $20 \mathrm{~dB}$ in the measurement of $40 \mathrm{kHz}$ signal using a lock-in amplifier with the time constant of $100 \mathrm{~ms}$, in Tokyo. This means that the calibration using the broadcast signal is practical because the signal to noise ratio is easily improved by the employment of longer time constant.

\section{References}

Clayton, M.D., C. Polk, H. Etzold and W.W. Cooper, Absolute Calibration of Antennas at Extreme1y Low Frequencies, IEEE Trans., AP-21, 514-523, 1973.

Echizenya, Y., T. Takeuchi and Y. Takenoshita, Appearance of winter anomaly phenomena in the field intensity of $L F$ radio wave propagation from Tokyo to Akita, Rev. Rad. Res. Labs., 20, 439-445, 1974. (in Japanese)

Ishii, M., T. Kawamura, J. Hojyo, K. Kaneko, T. Iwaizumi and E. Hori, Discussion on the Onset Condition of Anomalous Counts on Lightning Flash Counter, National Conv. Rec. of IEE Japan, 986, 1979. (in Japanese)

Ishii, M., T. Kawamura, J. Hojyo, K. Kaneko, T. Iwaizumi and E. Hori, Development of the Improved Vertical Antenna Type Lightning Flash Counter, Proc. Soc. Atmos. Elect. Japan, No 19, 120-123, 1978. (in Japanese)

Prentice S.A., D. Mackerras and R.P. Tolmie, Development and field testing of a vertical-aerial lightning-flash counter, Proc. IEE, 122, 487-491, 1975. 